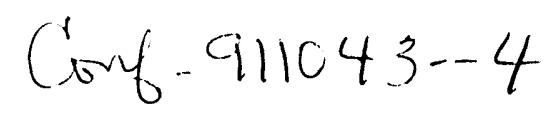

PNL-SA- -19355

DE92 004506

\title{
U.S DEPARTMENT OF ENERGY PARTICIPATION \\ IN THE DEVELOPMENT OF EMERGENCY RESPONSE \\ PLANNING GUIDELINES: THE PROGRAM AND PROCESS
}

L. H. Munson

B. W. Holder

October 1991

Presented at the

30th Hanford Symposium on Health

and the Environment

October 29 - November 1, 1991

Richland, Washington

Work supported by

the U.S. Department of Energy

under Contract DE-ACO6-76P.LO 1830

Pacific Northwest Laboratory

Richland, Washington 99352

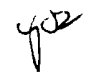

\section{DISCLAIMER}

This report was prepared as an account of work sponsored by an agency of the United States Government. Neither the United States Government nor any agency thereof, nor any of their employees, makes any warranty, express or implied, or assumes any legal liability or responsibility for the accuracy, completeness, or usefulness of any information, apparatus, product, or process disclosed, or represents that its use would not infringe privately owned rights. Reference herein to any specific commercial product, process, or service by trade name, trademark, manufacturer, or otherwise does not necessarily constitute or imply its endorsement, recommendation, or favoring by the United States Government or any agency thereof. The views and opinions of authors expressed herein do not necessarily state or reflect those of the United States Government or any agency thereof. 


\section{SiLS SA- 19355}

\section{U.S. Department of Energy Participation in the Development of Emergency Response Planning Guidelines: The Program and Process}

Brenda W. Holder, ${ }^{\text {L Leo H. Munson, }}{ }^{\mathrm{B}}$

${ }^{\text {ADepartment }}$ of Energy

${ }^{B}$ Pacific Northwest Laboratory 


\author{
U.S. Department of Energy Participation in the Development \\ of Emergency Response Planning Guidelines: The Program and Process
}




\section{Abstract}

Emergency response levels and protective action guides for incidents that could expose the public to an accidental release of radiation have been developed and used for many years. Similar attention, however, has not been focused on hazards from potential chemical releases. The tragic incident in Bhopal, India, in which over 2,000 people died and many survivors suffered irreversible health damage, has heightened concern worldwide about real and potential releases of chemicals. This concern, and the resultant re-evaluation by many companies, has demonstrated a need for similar guidelines for dealing with chemical hazards; such guidance would aid significantly in plant design and community planning.

To address the need for reliable, consistent, and well-documented emergency planning guidelines, a program of Emergency Response Planning Guidelines (ERPGs) was established by Organization Resources Counselors, Inc. (ORC). ORC, working through established task forces and the American Industrial Hygiene Association (AIHA), oversees ERPG development. The Department of Energy (DOE) participates in this program as a potential user of the resulting ERPGs and supports the development of ERPGs for chemicals used in DOE facilities and those that may be of particular concern in DOE's emergency response planning effort. This paper describes the program established for developing and issuing ERPGS and the process within DOE for providing support. 


\section{Introduction}

Occupational exposure guidelines and standards such as the American Conference of Governmental Industrial Hygienist's Threshold Limit Values (TLVs), the Occupational Safety and Health Administration's Permissible Exposure Limits (PELs), and the AIHA's Workplace Environmental Exposure Levels (WEELs) are inappropriate for evaluating short-term emergency exposures of high concentrations. These standards were all developed for worker protection and are based on daily exposures over a working lifetime. They use the time-weighted average concentration to which nearly all workers who work a normal 8-hour workday and 40-hour workweek may be repeatedly exposed, day after day, without adverse effects. These values also serve to protect against both acute and chronic health effects.

Several organizations have attempted to establish guidelines for emergency situations involving a single exposure to hazardous substances that may cause adverse health effects. The National Research Council (NRC) developed Emergency Exposure Guidelines Levels (EEGLs) principally for the Department of Defense and intended for healthy individuals. Realizing that the EEGLs were not applicable to the general population, the NRC developed the concept of "Short-term Public Emergency Guidance Levels" (SPEGLS); however, very few SPEGLs were ever developed.

During the 1960s, efforts to develop short-term exposure guidelines were made by several organizations, including the AIHA's Toxicology 
Committee, the American National Standards Institute (ANSI), and the Pennsylvania Department of Health. The guidelines from these organizations, however, were generally directed only to the occupational exposure and are not currently being updated.

During the late 1970s, the National Institute for Occupational Safety and Health (NIOSH) developed a series of values representing exposure levels that were "Immediately Dangeruus to Life and Health" (IDLHs). These values were used for identifying respiratory protection requirements in the NIOSH/OSHA Standards Completion Program. (1) Although several IDLHs were established, the Standards Completion Program itself ended, thereby ending further development of values. Nor are the existing values likely to be updated.

One of the inherent problems with using IDLHs is that they were intended for the workplace and do not take into account exposure of sensitive individuals such as children, the elderly, and asthmatics who are members of the general population. Furthermore, the 30-minute exposure time in many cases may not be realistic for accidental releases to the community. These IDLH values are not generally available, and the rationales and documentation were never peer-reviewed.

Some organizations, such as the World Bank and the European Econcmic Community, provided guidelines using acutely hazardous quantities rather than concentrations. These guidelines were based on a Lethal 
Concentration that will kill 50 percent of the test animals within a specified time $\left(L C_{50}\right)$, but they are inappropriate for emergency planning since lethality is the only health effect that was considered. Other important factors that were not considered were escape-impairing effects, data based on actual human experience, and serious but nonlethal effects, such as lung or other organ injuries. The National Fire Protection Association (NFPA) has developed a list of relative rankings from one to four to be used by emergency personnel as indicators for acute health hazards. These values, however, do not address the issue of airborne concentration, an important concern when planning for emergency situations.

\section{The ERPG Program}

Although various "emergency planning guidelines" have been recommended by several organizations, none of them, with the exception of the few NRC-SPEGLS, have been specifically developed for potential accidental release to the community. Recognizing the need for these values and responding to internal needs, several companies, each having reached the same conclusions, independently undertook development of the following emergency planning guidelines: ${ }^{(2)}$

1. The numbers are useful primarily for emergency planning and response.

2. The numbers are suitable for protection from health effects due to short-term exposures. They are not suitable for effects due to repeated exposures nor as ambient air quality guidelines. 
3. The numbers are guidelines. They are not absolute levels demarcating safe from hazardous conditions.

4. The numbers do not necessarily indicate levels at which specific actions must be taken.

5. The numbers are only one element of the planning activities needed to develop a program to protect the neighboring community.

6. The selection of chemicals needing emergency planning guidelines generally should be based on volatility, toxicity, aid releasable quantities.

Among those developing these guidelines, it became evident that there was a need for a consistent approach. Initially, ORC established a task force to address the need for reliable, consistent, and well-documented emergency response planning guidelines. Through the ORC ERPG Task Force, companies were willing to take an active role in the development of emergency guidance concentrations, and using a consistent procedure and approach, they were able to coordinate their efforts. Collectively, members of the ORC ERPG Task Force deveioped methods for establishing emergency exposure guidance levels and a list of chemicals for which ERPGs were believed to be needed. Today, the Task Force no Tonger exists, and the role of the ORC now is to organize and coordinate the efforts of participating companies as they make commitments to develop ERPGs for selection of chemicals according to the methods developed by the Task Force. The AIHA has established a technical committee comprised of heaith professionals to formally review, revise, and 
approve ERPGs submitted by the ORC. After final approval by the AIHA ERPG Committee, ERPGs are published and made available by the AIHA.

The ORC and AIHA working groups agreed to several general principles for the ERPG values. These principles are intended to provide estimites of concentration-ranges of a specific substance that would probably produce the adverse effects described in the definitions of ERPG-1, ERPG-2, and ERPG-3. Each of these levels is defined and briefly discussed below: ${ }^{(2)}$

ERPG-1 is the naximum airborne concentration below which it is believer that nearly all individuals could be exposed for up to 1 hour without experiencing other than mild transient adverse health effects or perceiving a clearly defined objectionable odor.

The ERPG-1 identifies a level which does not pose a health risk to the community but which may be noticeable due to slight odor or mild irritation. If a small, nonthreatening release occurred, the community could be notified that they may notice an odor or slight irritation but that the concentrations are below those which could cause adverse health effects.

ERPG-2 is the maximum airborne concentration below which it is believed that nearly all individuals could be exposed for up to 1 hour without xperiencing or developing irreversible or other 
serious health effects or symptoms which could impair an individual's ability to take protective actions.

Above the ERPG-2 level, for some members of the community, there may be significant adverse health effects or symptoms that could impair an individual's ability to take protective actions. These symptoms might include severe eye or respiratory irritation or muscular weakness.

ERPG-3 is the maximum airborne concentration below which it is believed that nearly all individuals could be exposed for up to 1 hour without experiencing or developing life-threatening health effects.

The ERPG-3 level is a worst-case planning level; to exceed it would result in health effects that are life-threatening to some members of the community. This guidance level would, therefore, be used in determining whether or not to initiate steps to mitigate any potential release of a particular chemical in a particular quantity.

In developing an ERPG for a chemical, it is important to emphasize the following:

- acute or short-term exposure data.

- both immediate and delayed health effects

- adverse reproductive, developmental, or carcinogenic effects

- data based on actual human experience. 
In the absence of data based on human experience, data from animal tests often form the basis for the ERPGs. The most pertinent information is that derived from acute inhalation toxicity stucies that have included clinical observations and histopathology. The focus is on the highest levels that do not produce the effects described by the definitions of the various ERPG levels. Next, data from repeat studies of chronic inhalation exposure with clinical and pathologic examination are considered. Following these in importance are studies of the basic, typically acute exposure where mortality is the major focus. When inhalation toxicity data are either unavailable or limited, data from studies involving other routes of exposure will be considered. of course, more value is giver to the more rigorously conducted studies. If the mechanistic or dose-response data are available, these data are applied when appropriate. (2)

Because each chemical may have a different dose-response curve, and because data of different amounts and qualities about any given chemical will produce varying predictions about the effects of releasing that particular chemical, each ERPG must be considered on a case-by-case basis. There is neither a formula nor a fixed relationship between the ERPG-1, ERPG-2, or ERPG-3 values.

Since there is a range of time periods that might be considered for these guidelines, the decision was made to focus on the 1-hour time period, because of the availability of toxicity information, and on a 
reasonable estimate for an exposure scenario. The user who may choose to extrapolate these values to other time periods is cautioned to review the documentation fully because such extrapolations tend to hold only over limited time periods, if at all. (2)

\section{The Process}

During early 1990, DOE's Office of Quality Programs issued a memorandum to DOE's Field Operations for a "Review of Chemicals as to Priority in Development of Emergency Response Planning Guidelines (ERPGs)." The criteria requested that the participants check the list for chemicals that have a potential for airborne concentrations that could, during normal operations or during an accident, cause adverse health effects to outdoor workers or the public. The parameters to be considered for determining whether to include any chemical or chemicals in the list were as follows: the size of discrete units of inventory in storage or shipment, the density and vapor pressure of the compound, the maximum possible rate of release, the number of persons that could be exposed, and the toxicity. Using these criteria, a prioritization on a scale of 1 to 5 , where 1 was the most urgent and 5 the least urgent, was requested. From this list, the first DOE ERPGs were selected. They were for uranium hexafluoride, nitric acid, sodium hydroxide, beryllium, chlorine trifluoride, and dimethylformamide. These DOE DRAFT ERPGs were submitted to ORC in september 1990.

The Subcommittee on Dose Assessment assigned three of its members, a 
toxicologist, an industrial hygienist, and a chemist, as an Ad Hoc Working Group with the responsibility of prioritizing the original DOE Operations ERPG 1ist. In order to avoid duplica ion of effort with other organizations, the DOE met with ORC and the AIHA ERPG Committee to discuss the next six proposed DOE prepared ERPGs. Currently under development are ERPGs for arsine, perchloroethylene, hydrogen peroxide, phosphine, trichlorethylene, and hydrazine. (An ERPG for toluene diisocyanate is being prepared by the International Institute of Isocyanates.) The ERPGs are completed and undergoing peer review. The Subcommittee on Dose Assessment has a Toxicologist Working Group that peer-reviews the Draft DOE ERPGs before submitting them to the ORC and the AIHA ERFa Committee. As soon as the peer review is completed, each will be submitted to ORC and the AIHA ERPG Committee.

In conclusion, ERPGs are general reference levels based on the best judgment of the specialist using the best available data, and are intended to be used in an overall emergency planning program. (2) The levels are not, and were never intended, to be used as safe limits for routine operations, or as definitive delineators between safe and unsafe exposure conditions, or as a basis for quantitative risk assessment. It is important to note that ERPGs should be applicable to nearly all individuals in the general population; however, in any population there may be hypersensitive individuals who have adverse responses at exposure concentrations far below levels where most individuals would respond. Furthermore, since ERPGs have been derived as planning and emergency 
response quidelines, they do not contain safety factors that are normally incorporated into exposure guidelines. They are estimates of the concentrations above which there would be an unacceptable likelihood of observing the defined effects. ${ }^{(2)}$ In some cases, the data may be limited and these estimates could have a large degree of uncertainty using the given values; therefore, users of ERPG values are strongly encouraged to carefully review the entire ERPG document before applying the values.

ERPG values can be a useful tool to determine what action should be taken when planning for, and responding to, a given chemical emergency, but effective emergency planning also requires careful evaluation of site-specific or situation-specific factors, including on-site workers and the public. Careful consideration should be given to the following concerns: the fact that the 1-hour ERPG value presumes no differences in variables (either human or nonhuman) at different times of the day; the possibility of emergencies of either shorter or longer duration than an hour; the population at special risk, such as the elderly or the young; and other factors, such as storage quantity, release rates, volatility, inventory, weather conditions, dersity and vapor pressure, and terrain.

\section{Acknowledgment}

Pacific Northwest Laboratory is operated for the U.S. Department of Energy by Battelle Memorial Institute under Contract DE-ACDG-76RLO 1830. 
References

(1) Alereeff, G. V.; Lipsett, M. J.; and Kizer, K. W.: Problems Associated with the Use of Immediately Dangerous to Life and Health (IDLH) Values for Estimating the Hazard of Accidental Chemical Releases. Amer. Indust. Hygiene Assoc. J. 50(11):598-605 (1989).

(2) American Industrial Hygiene Association ERPG Committee: Concepts and Procedures for the Development of Emergency Response Planning Guidelines (ERPGs), (December, 1989). 

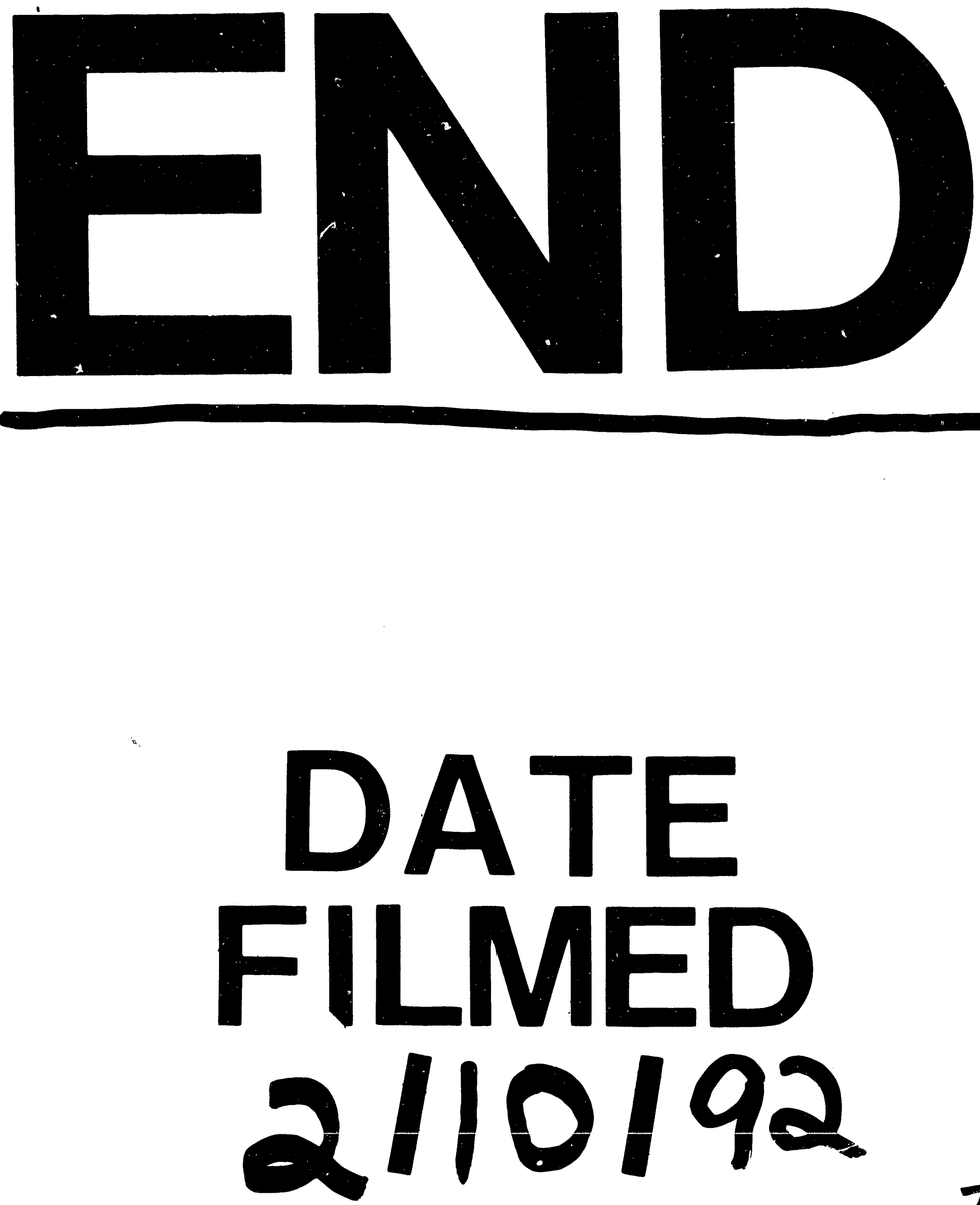

$I$ 
